\title{
Structural variations in aromatic $2 \pi$-electron three-membered rings of the main group elements
}

\author{
DIBYENDU MALLICK and ELUVATHINGAL D JEMMIS* \\ Department of Inorganic and Physical Chemistry, Indian Institute of Science, Bangalore 560 012, India \\ e-mail: jemmis@ipc.iisc.ernet.in
}

MS received 6 January 2014; accepted 8 July 2014

\begin{abstract}
Structural variations of different $2 \pi$-aromatic three-membered ring systems of main group elements, especially group 14 and 13 elements as compared to the classical description of cyclopropenyl cation has been reviewed in this article. The structures of heavier analogues as well as group 13 analogues of cyclopropenyl cation showed an emergence of dramatic structural patterns which do not conform to the general norms of carbon chemistry. Isolobal analogies between the main group fragments have been efficiently used to explain the peculiarities observed in these three-membered ring systems.
\end{abstract}

Keywords. Three-membered ring; $2 \pi$-aromaticity; isolobal analogy; non-planarity.

\section{Introduction}

Thought processes in the structural chemistry of main group elements are influenced largely by the chemistry of the first row elements, especially that of carbon. This is especially true of aromaticity. Benzene is the ideal aromatic compound to which all other systems are compared. This remains true even for $2 \pi$-electron aromatics. Synthesis and structural characterization of the planar $2 \pi$-aromatic cyclopropenyl cation and its derivative was the beginning of this exploration. ${ }^{1}$ The electronic structure description of cyclopropenyl cation in terms of the Walsh orbitals for the bonding in the in-plane threemembered ring skeleton, ${ }^{2}$ the three $2 \mathrm{c}-2 \mathrm{e}$ bonds of the exocyclic bonds and the $2 \pi$-aromaticity ${ }^{3}$ have stood in good stead over the years. Isoelectronic replacement of a carbon of the ring by other group elements is expected to retain this description. Yet, experimental observations indicate dramatic variations that exist outside the norms of carbon chemistry. The basic unit of tetrahedral tetracoordination of carbon is not followed among many heavier elements of the same group. Over the years, we have studied a variety of saturated and unsaturated three-membered rings involving main group elements. Our attempt has been to start with two wellknown organic structures, the cyclopropenyl cation (1) and the cyclopropane (2), and explore the dramatic variations that emerge when the carbon atoms are replaced by other elements of the same period such as boron and heavier elements of their groups (figure 1). We

\footnotetext{
*For correspondence
}

concentrate here more on instances where there is substantial deviation from the description of cyclopropenyl cation.

It is difficult to imagine that $\mathrm{Ge}_{3} \mathrm{H}_{3}^{+}$, and heavier analogues prefer a structure with bridging hydrogens, $\mathbf{3}$ (figure 2). ${ }^{4}$ Nor is it possible to guess that $\mathrm{Pb}_{3} \mathrm{H}_{6}$, while retaining the three-membered ring structure, twists each $\mathrm{PbH}_{2}$ group cyclically to obtain a $C_{3 h}$ structure 4 (figure 2), even though a bridged structure 5 (figure 2) is lower in energy. ${ }^{5}$ While these appear abnormal, there are several X-ray structures of the three-membered rings which belong to these categories. For example, $\mathrm{Ga}_{3} \mathrm{R}_{3}^{2-}$ (6, figure 2) which is isoelectronic to $\mathrm{C}_{3} \mathrm{H}_{3}^{+}$has a $C_{3 h}$ geometry. ${ }^{6}$ Similarly, the plumbacyclopropane effectively has a three-membered ring skeleton with $C_{3 h}$ symmetry. We review here the structural patterns that emerge in these substitutional processes and explain these structural variations, largely selected from our results.

\section{Structures of cyclopropenyl cation and its heavier analogues}

We begin with a studyto see how far the structure of $\mathrm{C}_{3} \mathrm{H}_{3}^{+}$serves as a general model for the heavier analogues $\mathrm{A}_{3} \mathrm{H}_{3}^{+}(\mathrm{A}=\mathrm{Si}, \mathrm{Ge}, \mathrm{Sn}$ and $\mathrm{Pb})$. A detailed study on group 14 analogues of the cyclopropenyl cation indicated that $\mathrm{C}_{3} \mathrm{H}_{3}^{+}$and $\mathrm{Si}_{3} \mathrm{H}_{3}^{+}$prefer the classical $D_{3 h}$ structure (7, figure 3 ) as the most stable ones. ${ }^{4,7}$ However, $\mathrm{Ge}_{3} \mathrm{H}_{3}^{+}, \mathrm{Sn}_{3} \mathrm{H}_{3}^{+}$, and $\mathrm{Pb}_{3} \mathrm{H}_{3}^{+}$adopt a H-bridged $C_{3 v}$ structure (8, figure 3 ) over classical $D_{3 h}$ structure. All H-bridged $C_{3 v}$ structures (8) are minima with the exception of $\mathrm{C}_{3} \mathrm{H}_{3}^{+}$, for which it is not a stationary 

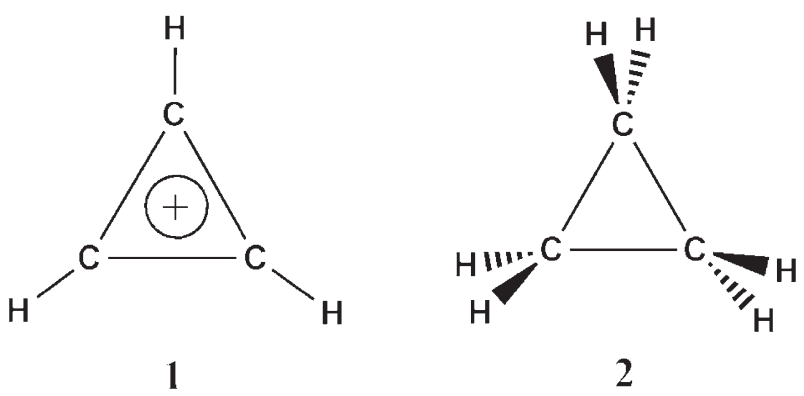

Figure 1. Structure of cyclopropenyl cation (1) and cyclopropane (2).

point on the Potential energy surface (PES). Upon optimization, it leads to another $\mathrm{H}$-bridged planar structure with $D_{3 h}$ symmetry (10, figure 3 ), which is a thirdorder saddle point. The NBO analysis of the H-bridged non-planar $C_{3 v}$ structures of $\mathrm{A}_{3} \mathrm{H}_{3}^{+}(\mathbf{8})$ shows that the $\mathrm{A}-\mathrm{H}$ bond atomic orbitals for $\mathrm{A}=\mathrm{Ge}, \mathrm{Sn}$ and $\mathrm{Pb}$, have nearly pure $p$-character and high percentage of $s$ character of the lone pair orbitals. Greater stability of the bridged $C_{3 v}$ structure over classical $D_{3 h}$ structure for heavier species is due to their reluctance of using the valence $s$ orbital in bonding. Increase in $\mathrm{A}-\mathrm{A}$ bond length reduces the strength of $\pi$ bonding. Higher preferences of the bridged structures as compared to the classical structure for heavier analogues of $\mathrm{C}_{3} \mathrm{H}_{3}^{+}$can also be analysed in terms of the preference of protonation of $\mathrm{A}_{3}^{2-}$ anion (11, scheme 1), which has two different protonation sites. Structures $\mathbf{7}$ and $\mathbf{8}$ can be formed by either protonating at the lone pairs (which leads to the $\mathrm{A}-\mathrm{H}$ bond formation in 7) or at the $\mathrm{A}-\mathrm{A}$ bond giving rise to $\mathrm{A}-\mathrm{H}-\mathrm{A}$ bridges in $\mathbf{8}$ or $\mathbf{9 / 1 0}$ as shown in scheme 1 . As we go down the group, the heavier elements tend to prefer divalent arrangements owing to their propensity to hold lone pairs on themselves. This behaviour is reflected in the $\%$ of $s$ orbital contribution in the $\mathrm{A}_{3}^{2-}$ lone pairs, which increases in the order $47>72>80>82>88$ as we go from $\mathrm{C}$ to $\mathrm{Pb}$. Hence, protonation at the $\mathrm{A}-\mathrm{A}$ bond will be easier than that of the lone pairs for heavier elements which eventually leads to the bridged structure. Thus, heavier elements have periodic variations of their own.

\section{Group 13 analogues of cyclopropenyl cation}

The group 13 analogs of cyclopropenyl cation where only one carbon atom is replaced are neutral. The boron analogue of cyclopropenyl cation, borirene, $\mathrm{C}_{2} \mathrm{BH}_{3}(\mathbf{1 2}$, figure 4) is estimated to be stable and its derivative has been synthesized (13, figure 4). ${ }^{8}$ Synthesis of borirene by the reaction of pulsed beam of boron atoms with unsaturated hydrocarbons such as ethylene has been reported. ${ }^{9}$ The resonance stabilization energy of borirene is only about $70 \%$ of that of $\mathrm{C}_{3} \mathrm{H}_{3}^{+} .{ }^{10}$ The gas phase synthesis of neutral and ionic $\mathrm{AlC}_{2} \mathrm{H}_{4}$ provided another dimension to the three-membered ring chemistry. ${ }^{11}$

Schleyer and coworkers calculated the relative energies of the isomers of isoelectronic diboriranyl anion, $\mathrm{CB}_{2} \mathrm{H}_{3}^{-}$(14, figure 4) and showed that the threemembered ring structure with $C_{2 v}$ symmetry is the most stable one. ${ }^{12}$ Though the parent diboriranyl anion has not yet been identified conclusively, its derivative with bulky substituents has been successfully isolated and characterized by NMR (15, figure 4). ${ }^{13}$

Replacement of the $\mathrm{CH}$ groups by isolobal $\mathrm{BH}^{-}$ groups in the $\mathrm{C}_{3} \mathrm{H}_{3}^{+}$gives $\mathrm{B}_{3} \mathrm{H}_{3}^{2-}$. Computational studies show that the minimum energy structure of $\mathrm{B}_{3} \mathrm{H}_{3}^{2-}$ has a $D_{3 h}$ geometry $\left(\mathbf{1 6}\right.$, scheme 2) similar to that of $\mathrm{C}_{3} \mathrm{H}_{3}^{+}$ ion. ${ }^{14}$ Sequential protonation of $\mathrm{B}_{3} \mathrm{H}_{3}^{2-}$ generates structures $\mathrm{B}_{3} \mathrm{H}_{4}^{-}, \mathrm{B}_{3} \mathrm{H}_{5}$ and $\mathrm{B}_{3} \mathrm{H}_{6}^{+}$(scheme 2). ${ }^{14 \mathrm{a}, \mathrm{d}, \mathrm{e}, 15}$ All these species are aromatic in nature with $2 \pi$ electrons. The most stable isomer of $\mathrm{B}_{3} \mathrm{H}_{4}^{-}$has planar structure (17) with one bridging hydrogen atom. Second protonation on $\mathrm{B}_{3} \mathrm{H}_{3}^{2-}$ generates $\mathrm{B}_{3} \mathrm{H}_{5}(\mathbf{1 8})$, which has a planar $2 \pi$-aromatic structure with two bridging hydrogen atoms. It is expected that the introduction of the third proton will give rise to a structure where all the three

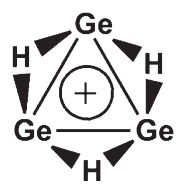

3

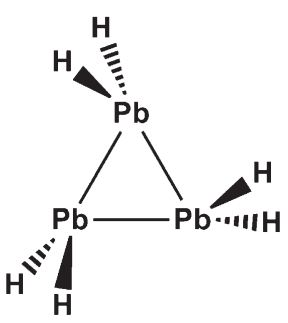

4

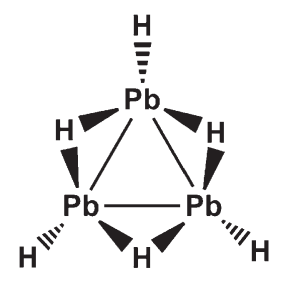

5

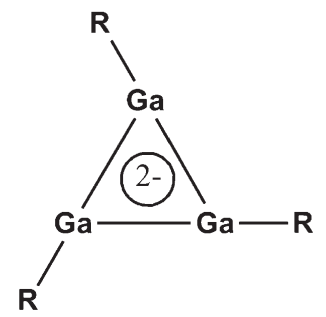

6

Figure 2. Structure of cationic $\mathrm{Ge}_{3} \mathrm{H}_{3}^{+}$(3), the skewed and $\mathrm{H}$-bridged structure of $\mathrm{Pb}_{3} \mathrm{H}_{6}$ $(\mathbf{4}$ and $\mathbf{5})$ and dianionic $\mathrm{Ga}_{3} \mathrm{R}_{3}^{2-}(\mathbf{6})$. 


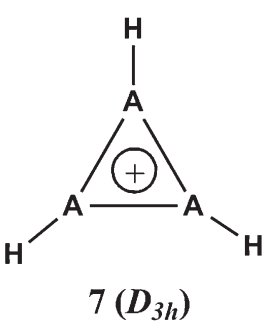

C

Si

Ge

Sn

Pb

$0.0(0)$

$0.0(0)$

$0.0(0)$

$0.0(1)$

$0.0(3)$

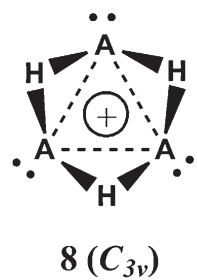

$-32.4(0)$

$-63.3(0)$<smiles></smiles>

$9\left(D_{3 h}\right)$

$10\left(D_{3 h}\right)$

$194.8(3)$

$55.6(3)$

53.5 (3)

$5.5(3)$

$-15.7(3)$

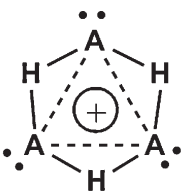

53.5 (3)

$-48.1(3)$

Figure 3. Schematic representation of cyclic isomers of $\mathrm{A}_{3} \mathrm{H}_{3}^{+}(\mathrm{A}=\mathrm{C}-\mathrm{Pb})$ cation. Relative energies in $\mathrm{kcal} / \mathrm{mol}$, number of imaginary frequencies in parentheses.

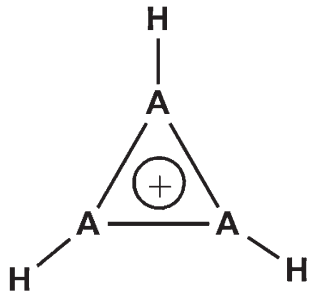

7

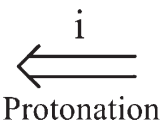

at

lone pair

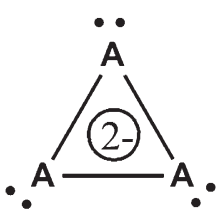

11
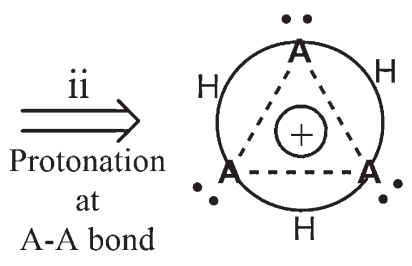

8,9 or 10

Scheme 1. Formation of classical (7) and non-classical bridged structures $(\mathbf{8}, \mathbf{9}$ or $\mathbf{1 0})$ through protonation of $\mathrm{A}_{3}^{2-}$ anion (11).

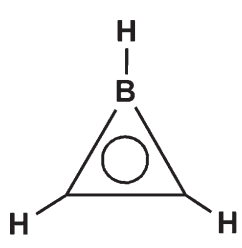

12

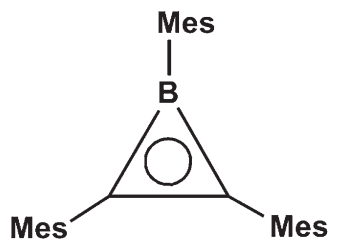

13

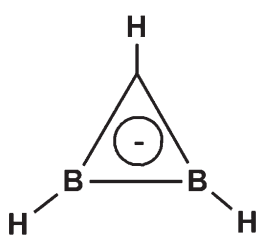

14

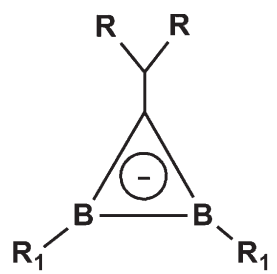

15

Figure 4. Borirene (12), derivative of borirene (Mes = Mesityl group) (13), Diboriranyl anion (14), and its derivative (15) $\left(\mathrm{R}=\mathrm{Si}\left(\mathrm{CH}_{3}\right)_{3}, \mathrm{R}_{1}=\mathrm{C}\left(\mathrm{CH}_{3}\right)_{3}\right)$.

bridging and three terminal hydrogen atoms remain in the plane of the $\mathrm{B}_{3}$ ring. However, it is found that the planar $D_{3 h}$ structure (20, figure 5) is a transition state and the non-planar $C_{3 v}$ aromatic structure (19, figure 5) is the most stable isomer. This is regarded as the first three-membered nonplanar $2 \pi$-aromatic system, which is known in gas phase and its derivative was recently synthesized. ${ }^{16}$
What is the reason for the non-planarity of the bridging and terminal hydrogens in the most stable structure of $\mathrm{B}_{3} \mathrm{H}_{6}^{+}$? Detailed electronic structures of $\mathrm{B}_{3} \mathrm{H}_{5}$ and $\mathrm{B}_{3} \mathrm{H}_{6}^{+}$provide an explanation. The Molecular Orbitals (MOs) of $\mathrm{B}_{3} \mathrm{H}_{5}$ can be constructed from $\mathrm{B}_{3} \mathrm{H}_{3}$ and $\mathrm{H}_{2}$ fragment MOs. The three in-plane Walsh orbitals $\left(\mathrm{a}_{1}^{\prime}\right.$ and $\left.\mathrm{e}^{\prime}\right)$ and the $\pi-\mathrm{MO}\left(\mathrm{a}_{2}^{\prime \prime}\right)$ of the $\mathrm{B}_{3} \mathrm{H}_{3}$ ring are shown in figure 6 . 


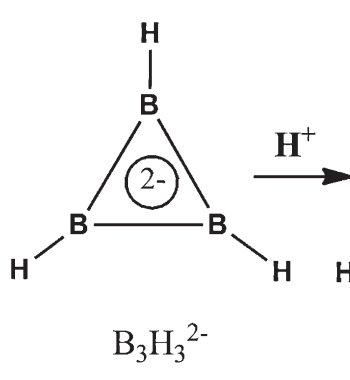

16

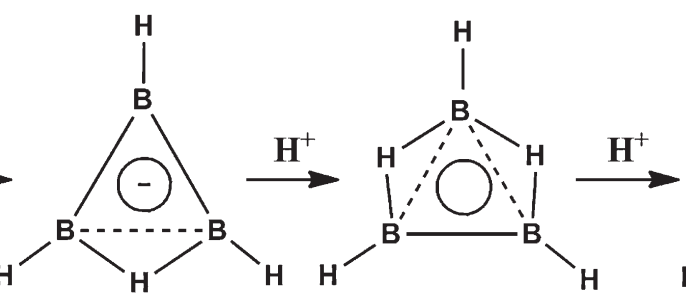

$\mathrm{B}_{3} \mathrm{H}_{4}^{-}$

17

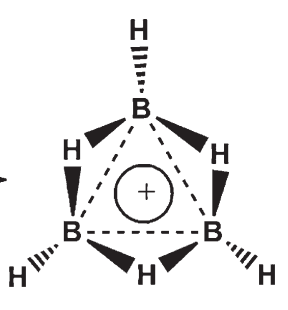

$\mathrm{B}_{3} \mathrm{H}_{6}^{+}$

19

Scheme 2. Sequential protonation of $\mathrm{B}_{3} \mathrm{H}_{3}^{2-}$ to $\mathrm{B}_{3} \mathrm{H}_{6}^{+}$.

Interactions of degenerate $\mathrm{e}^{\prime}$ orbitals of the $\mathrm{B}_{3} \mathrm{H}_{3}$ ring with the bonding and antibonding MOs of $\mathrm{H}_{2}$ lead to stabilization of the respective MOs. Similarly, the MOs of planar $\mathrm{B}_{3} \mathrm{H}_{6}^{+}$can be constructed from $\mathrm{B}_{3} \mathrm{H}_{3}$ and $\mathrm{H}_{3}^{+}$ fragment MOs. ${ }^{17}$ The degenerate MOs of the $\mathrm{H}_{3}^{+}$find a profitable interaction with the degenerate $\mathrm{e}^{\prime}$ orbitals of $\mathrm{B}_{3} \mathrm{H}_{3}$. On the other hand, the $\mathrm{a}_{1}^{\prime}$ orbitals of planar $\mathrm{B}_{3} \mathrm{H}_{3}$ and $\mathrm{H}_{3}^{+}$fragments do not interact strongly because they are directed away from each other. The $\mathrm{a}_{1}^{\prime}$ orbital of $\mathrm{H}_{3}^{+}$cannot interact with the $\pi-\mathrm{MO}$ of the borocyclic ring because it is in the nodal plane of the $\pi-\mathrm{MO}$ and hence overlap is zero. A correlation diagram between the planar and the non-planar $\mathrm{B}_{3} \mathrm{H}_{6}^{+}$shows a dramatic stabilization of the $\pi$-MO in going from planar $\left(D_{3 h}\right)$ to non-planar $\left(C_{3 \mathrm{v}}\right)$ structure (figure 7$) .{ }^{17}$ In the non-planar structure, the totally symmetric $\mathrm{MO}\left(\mathrm{a}_{1}^{\prime}\right)$ of $\mathrm{H}_{3}^{+}$will find the right symmetry to interact with the $\pi-\mathrm{MO}$ of $\mathrm{B}_{3} \mathrm{H}_{3}$ ring and hence, stabilizes it.

Steric repulsion between the terminal hydrogen and the bridging hydrogen in the planar structures may also contribute to their instability over the non-planar

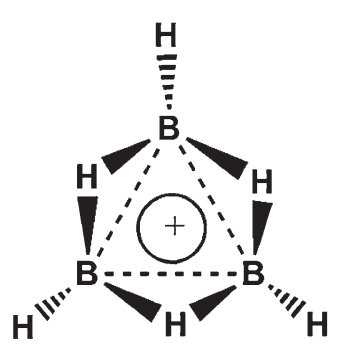

19

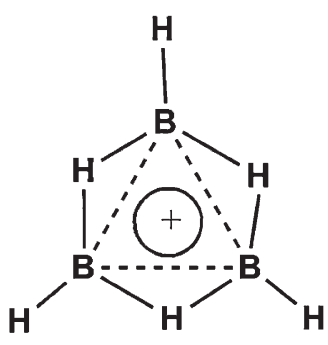

20

37.9 (1)
Figure 5. Structures $\mathbf{1 9}$ and 20, relative energies $(\mathrm{kcal} / \mathrm{mol})$ at the B3LYP/6-311++G** level of theory and the number of imaginary frequencies (in parentheses) for $\mathrm{B}_{3} \mathrm{H}_{6}^{+}$. structure. Distance between the terminal hydrogen $\left(\mathrm{H}_{\mathrm{t}}\right)$ and the bridging hydrogen $\left(\mathrm{H}_{\mathrm{b}}\right)$ increases from 1.88 $\AA$, which is an unusually short $\mathrm{H}-\mathrm{H}$ non-bonded distance ${ }^{18}$ to $2.08 \AA$ as we go from planar to non-planar $\mathrm{B}_{3} \mathrm{H}_{6}^{+}$, and hence steric repulsion is minimized. In this context, it is important to note that substituents have a large influence on the structure and stability of the three-membered borocyclic rings. Ab initio calculations showed that the lithiated derivatives of $\mathrm{B}_{3} \mathrm{H}_{6}^{+}$prefer a planar structure. ${ }^{17}$

Isolobal analogy has been a powerful tool to build bridges between organic and inorganic chemistry. Apart from these, the analogy has been instrumental in predicting new molecules with various unique bonding patterns. For example, the Dewar-Chatt-Duncanson (DCD) model explains the bonding in metal-olefin $\pi$ complexes through $\sigma$ donation and $\pi$ back donation between ligand and metal. According to this model, the back donation happens from filled metal d-orbital to the $\pi^{*}$ orbital of the ligand. However, isolobal replacement of $\mathrm{B}-\mathrm{H}$ group in $\mathrm{B}_{3} \mathrm{H}_{5}$ by appropriate metal fragment makes an interesting case. Replacement of one of the $\mathrm{B}-\mathrm{H}$ fragments in $\mathrm{B}_{3} \mathrm{H}_{5}$ by 14 electron isolobal transition metal fragments such as $\mathrm{Cr}(\mathrm{CO})_{4}, \mathrm{Fe}(\mathrm{CO})_{3}$ or $\mathrm{Co}(\mathrm{Cp})$ leads to the structures 21-23 (figure 8 ) in which the $\mathrm{B}-\mathrm{B}$ distances decrease (1.64 $\AA, 1.60 \AA$ and $1.60 \AA$ for complex 21, 22 and 23, respectively) as compared to the same (1.75 $\AA$ ) in isolated planar $\mathrm{B}_{2} \mathrm{H}_{4}$ molecule (24). ${ }^{19}$ The bonding in 21 can be described by the interaction between the planar $\mathrm{B}_{2} \mathrm{H}_{4}$ fragment and the $\mathrm{Cr}(\mathrm{CO})_{4}$ fragment. The isolated planar $\mathrm{B}_{2} \mathrm{H}_{4}$ fragment has a vacant $\pi \mathrm{MO}$ (LUMO). The interaction diagram (figure 9) for complex 21 shows that the $\mathrm{B}_{2} \mathrm{H}_{4}$ acts as a four electron donor where the $2 \mathrm{~B}-\mathrm{H} \sigma$ bonds $\left(1 \mathrm{~b}_{1}\right.$ and $\left.1 \mathrm{a}_{1}\right)$ donate their electron pairs to the vacant d-orbitals $\left(1 b_{1}\right.$ and $\left.2 a_{1}\right)$ of the $\mathrm{Cr}(\mathrm{CO})_{4}$ fragment. Contrastingly, in this case, the back donation occurs from metal d-orbital $\left(1 b_{2}\right)$ to the vacant $\pi \mathrm{MO}$ (not $\pi^{*} \mathrm{MO}$ ) of $\mathrm{B}_{2} \mathrm{H}_{4}$, resulting 

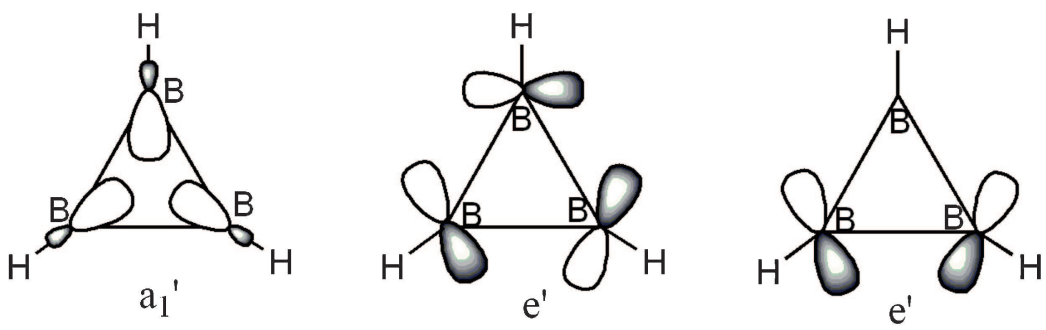

In-plane Walsh orbitals of the $\mathrm{B}_{3} \mathrm{H}_{3}$ ring

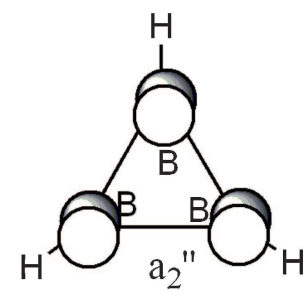

$\pi-\mathrm{MO}$ of $\mathrm{B}_{3} \mathrm{H}_{3}$

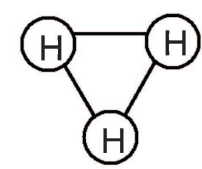

$\mathrm{a}_{1}{ }^{\prime}$

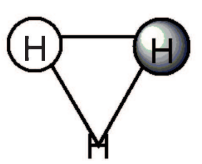

$\mathrm{e}^{\prime}$

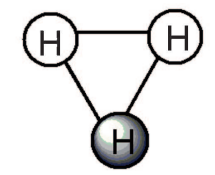

$\mathrm{e}^{\prime}$

Molecular orbitals of $\mathrm{H}_{3}{ }^{+}$

Figure 6. MOs of $\mathrm{B}_{3} \mathrm{H}_{3}$ and $\mathrm{H}_{3}^{+}$fragments.

in decrease in the $\mathrm{B}-\mathrm{B}$ bond length. Thus, we witness a unique case of bonding in this complex in which reversal of popular DCD model is observed. Follo wing the successful synthesis of a B-B triple bonded molecule,${ }^{20}$ this has been used to form a $\pi$ complex with platinum, which is a novel $\pi$ system where the $B-B$ $\pi$ bond is strengthened due to back $\pi$ donation from metal fragment, ${ }^{21}$ supporting such reversal of DCD model.

The three-membered rings with $2 \pi$ electrons take another dimension by the development of silaboranes, molecules composed of silicon, boron and hydrogen. Boron and silicon which are diagonally related in the periodic table are expected to exhibit much more interesting chemistry when they form mixed hydrides. The electronegativity of B and Si (2.0 and 1.8, respectively) are quite comparable. A novel entry to the compounds of silaboranes emerged with the analogy between the trivalent boron and divalent silicon. ${ }^{22}$ The isolobal analogy between the trivalent boron and divalent silicon is shown in scheme $3 .^{22}$

The two fragments, $\mathrm{BH}_{3}$ and $\mathrm{SiH}_{2}$ are termed as isolobal, where one of the $\mathrm{B}-\mathrm{H}$ bond pair orbital in $\mathrm{BH}_{3}$ is equated to the lone pair orbital in $\mathrm{SiH}_{2}$, leaving the perpendicular $p$ orbital in $\mathrm{BH}_{3}$ and $\mathrm{SiH}_{2}$ vacant. Based on this isolobal analogy, the structure of $\mathrm{SiB}_{2} \mathrm{H}_{4}$ (25, figure $\left.10 a\right)^{23}$ can be justified from $\mathrm{B}_{3} \mathrm{H}_{5}$ (18) by equating a $\mathrm{B}-\mathrm{H}$ bond to silicon with

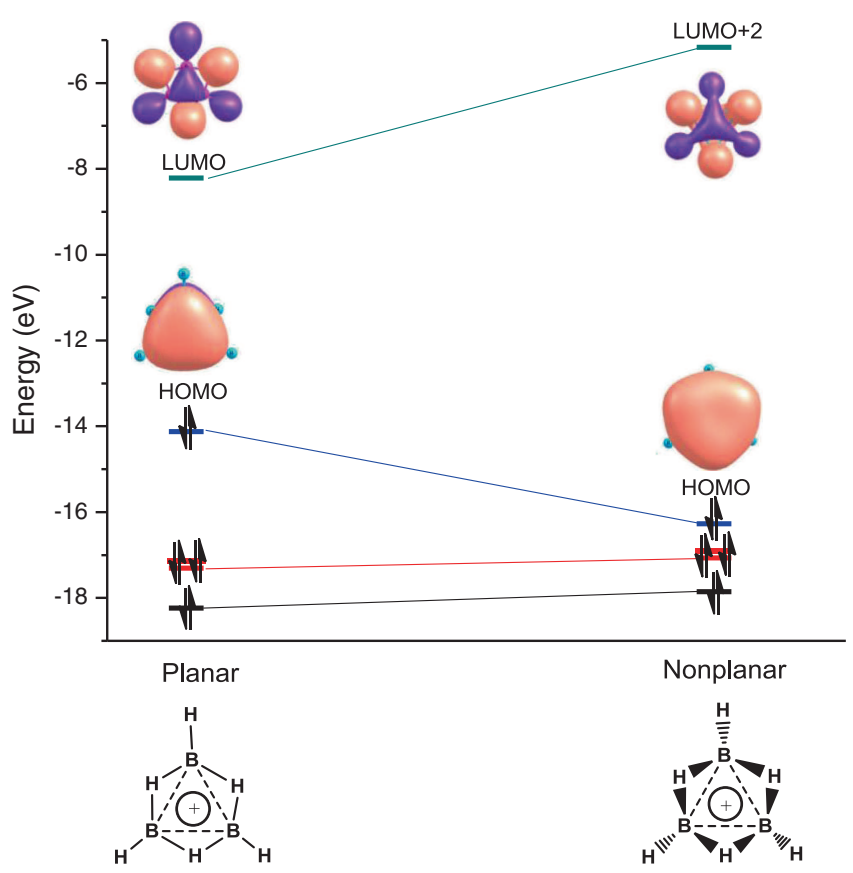

Figure 7. Correlation diagram showing a dramatic stabilization of the $\pi$-MO in going from planar $\left(D_{3 h}\right)$ to nonplanar $\left(C_{3 \mathrm{v}}\right)$ structure. 
(a)

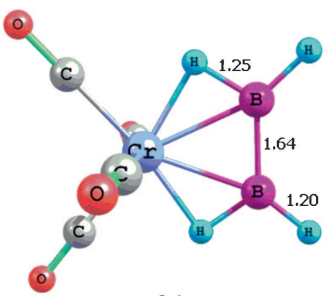

21

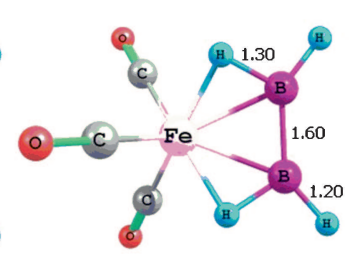

22

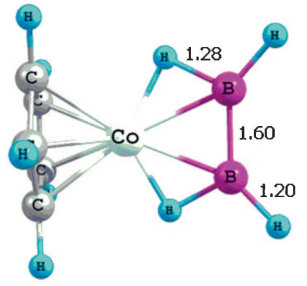

23 (b)

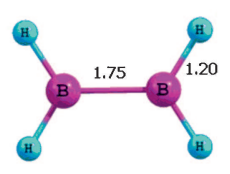

24

Figure 8. Structures of (a) $\mathrm{Cr}(\mathrm{CO}){ }_{4} \mathrm{~B}_{2} \mathrm{H}_{4}(\mathbf{2 1}), \mathrm{Fe}(\mathrm{CO})_{3} \mathrm{~B}_{2} \mathrm{H}_{4}(\mathbf{2 2}), \mathrm{Co}(\mathrm{Cp}) \mathrm{B}_{2} \mathrm{H}_{4}(\mathbf{2 3})$ and (b) isolated $\mathrm{B}_{2} \mathrm{H}_{4}(\mathbf{2 4})$.

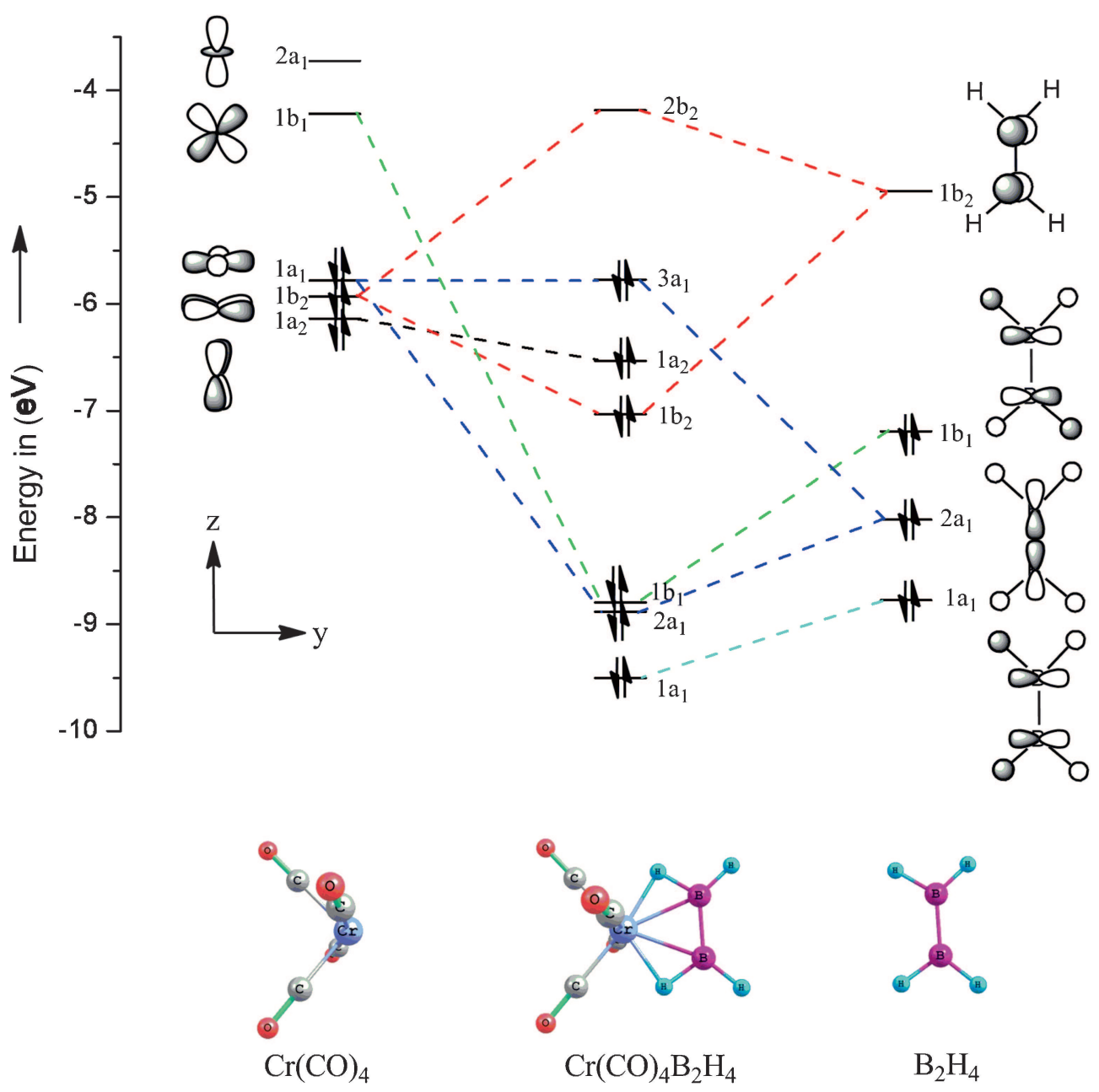

Figure 9. Interaction diagram showing the interaction between $\mathrm{B}_{2} \mathrm{H}_{4}$ and $\mathrm{Cr}(\mathrm{CO})_{4}$ fragments in $\mathrm{Cr}(\mathrm{CO})_{4} \mathrm{~B}_{2} \mathrm{H}_{4}$ complex.
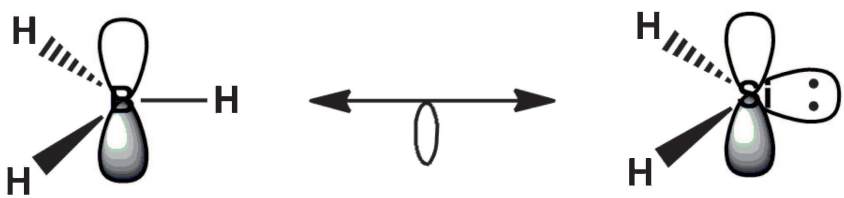

Scheme 3. Schematic representation of isolobal analogy between $\mathrm{BH}_{3}$ and $\mathrm{SiH}_{2}$. a lone pair. It has been found that $2 \pi$-aromatic structures with divalent silicon are lower in energy than the conventional H-bridged structure (26, figure 10a) envisaged for $\mathrm{SiB}_{2} \mathrm{H}_{4}$. In fact, the structure 26 is a transition state, unlike the carborane (28, figure $10 b)$, where it is reported to be a minimum. ${ }^{15 a}$ Tracing the direction of the imaginary frequency of $\mathbf{2 6}$ leads to a low symmetry structure $\mathbf{2 7}$, in which all the hydrogens 
(a)

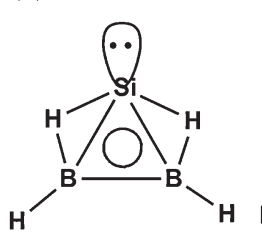

25

$0.0(0)$

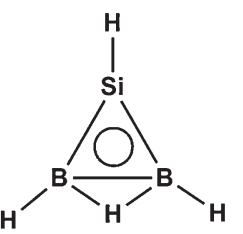

26

$19.4(1)$

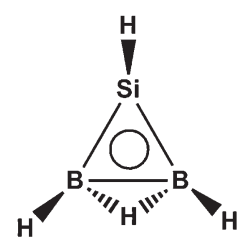

27

$17.5(0)$ (b)

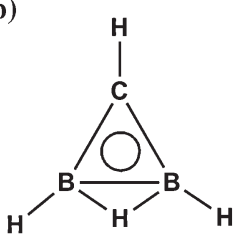

28 (c)

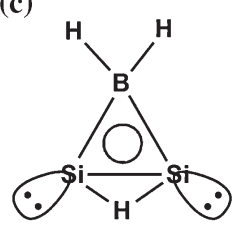

29

Figure 10. (a) Isomers of $\mathrm{SiB}_{2} \mathrm{H}_{4}$ and most stable structure of (b) $\mathrm{CB}_{2} \mathrm{H}_{4}$ and (c) $\mathrm{Si}_{2} \mathrm{BH}_{3}$. Relative energies (kcal/mol) at MP4/6-31G* level of theory, number of imaginary frequencies in parentheses.

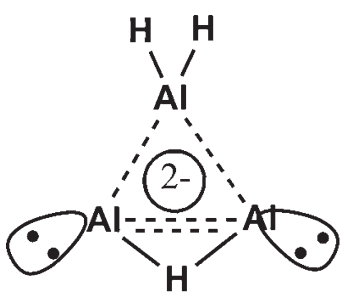

30

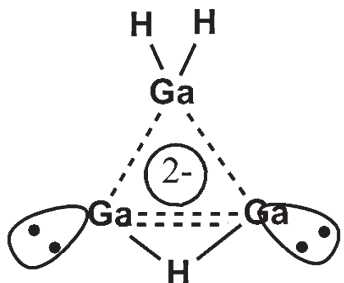

31
Figure 11. Most stable isomers of $\mathrm{Al}_{3} \mathrm{H}_{3}^{2-}$ (30) and $\mathrm{Ga}_{3} \mathrm{H}_{3}^{2-}$ (31).

lie outside the BBSi plane. The structure 27 is $17.5 \mathrm{kcal} / \mathrm{mol}$ higher in energy than the most stable isomer (25) of $\mathrm{SiB}_{2} \mathrm{H}_{4}$ at $\mathrm{MP} 4 / 6-31 \mathrm{G}^{*}$ level of theory. The chemistry of three-membered silaborane has been extended by studying the isomers of $\mathrm{Si}_{2} \mathrm{BH}_{3},{ }^{24}$ the neutral analogue of $\mathrm{Si}_{3} \mathrm{H}_{3}^{+}$. A cyclic $2 \pi$ electron delocalized structure (29, figure 10c) with a planar tetra-coordinated boron and a $3 \mathrm{c}-2 \mathrm{e} \mathrm{Si}-\mathrm{H}-\mathrm{Si}$ bond is reported as the global minimum. ${ }^{24}$

It is evident that there is a significant difference in the silicon chemistry as compared to the carbon analogue. It has been found to be true for the elements of group 13 also. Study of the homocyclic three-membered

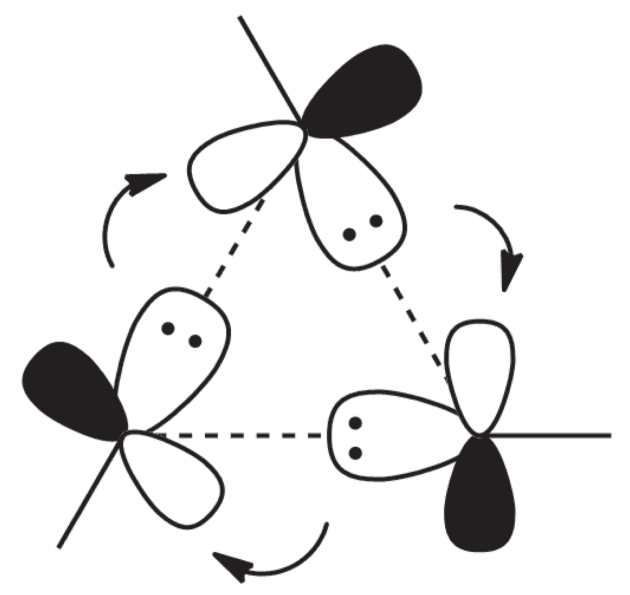

Scheme 4. Interaction of the $\sigma$ lone pairs with the $p$ orbitals of $\mathrm{Ga}-\mathrm{H}$ fragments.

hydrides of group 13 elements (B, Al, Ga) showed that the three-membered ring structures composed of $\mathrm{Al}$ and $\mathrm{Ga}$ exhibit different structural properties in comparison to boron. ${ }^{25}$ For example, the most stable structures of $\mathrm{Al}_{3} \mathrm{H}_{3}^{2-}$ (30, figure 11) and $\mathrm{Ga}_{3} \mathrm{H}_{3}^{2-}$ (31, figure 11) are the hydrogen-bridged structures with planar tetra-coordinated heavy atoms; whereas for $\mathrm{B}_{3} \mathrm{H}_{3}^{2-}$, a structure with three terminal hydrogens is the global minimum. These isomers (30 and $\mathbf{3 1}$ ) are 1.8 and

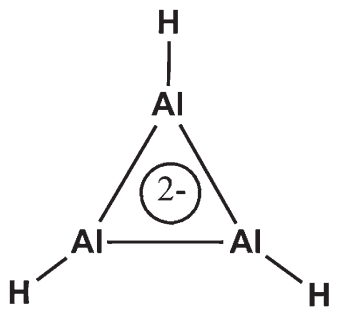

32

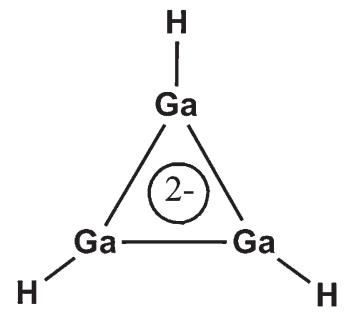

33

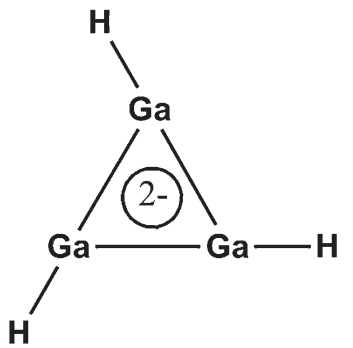

6

Figure 12. Classical $\mathrm{D}_{3 \mathrm{~h}}$ structures of $\mathrm{Al}_{3} \mathrm{H}_{3}^{2-}(\mathbf{3 2}), \mathrm{Ga}_{3} \mathrm{H}_{3}^{2-}(\mathbf{3 3})$ and the $C_{3 h}$ structure of $\mathrm{Ga}_{3} \mathrm{H}_{3}^{2-}$ (6). 


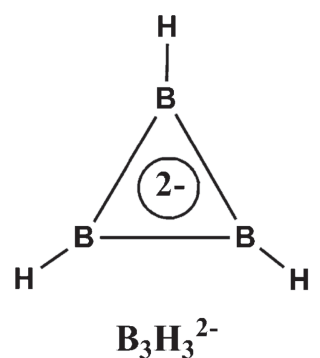

16

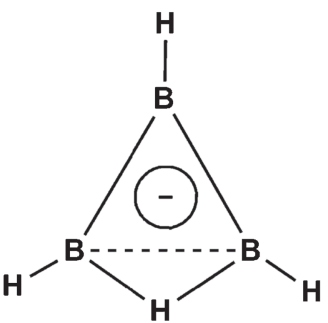

$\mathrm{B}_{3} \mathrm{H}_{4}{ }^{-}$

17

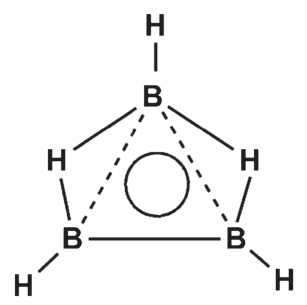

$\mathrm{B}_{3} \mathrm{H}_{5}$

18

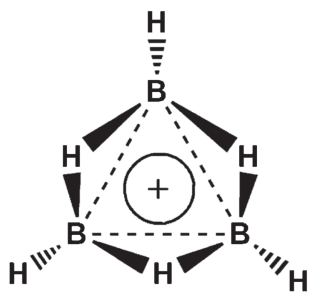

$\mathbf{B}_{3} \mathbf{H}_{6}^{+}$

19

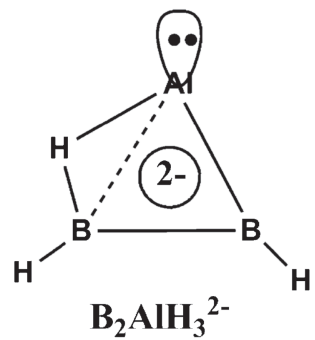

34

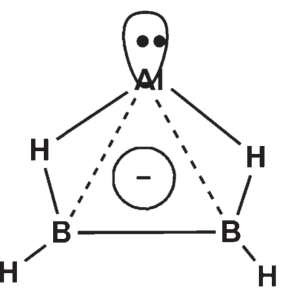

$\mathrm{B}_{2} \mathrm{AlH}_{4}$

35

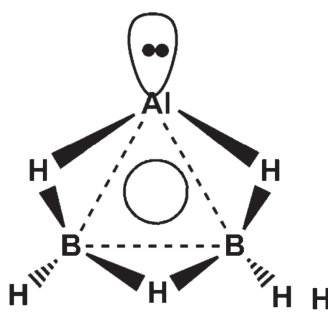

$\mathbf{B}_{2} \mathrm{AlH}_{5}$

36

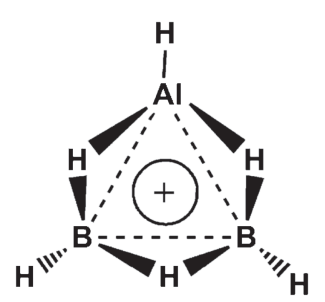

$\mathrm{B}_{2} \mathrm{AlH}_{6}^{+}$

37

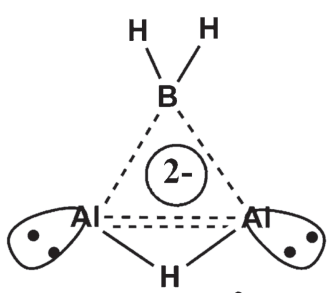

$\mathrm{BAl}_{2} \mathrm{H}_{3}{ }^{2-}$

38

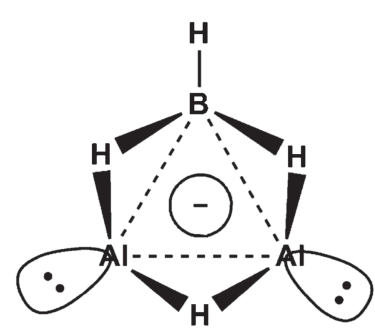

$\mathrm{BAI}_{2} \mathrm{H}_{4}^{-}$

39

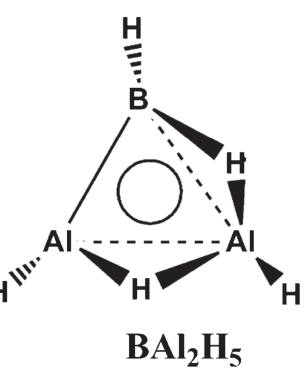

40

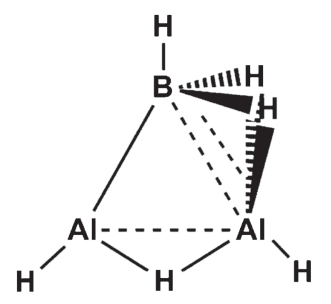

$\mathrm{BAl}_{2} \mathrm{H}_{6}^{+}$

41

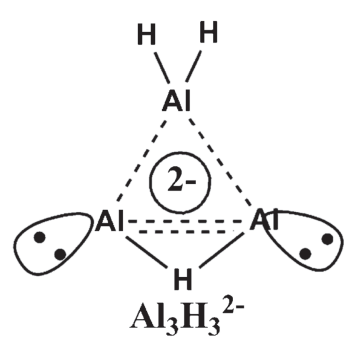

30

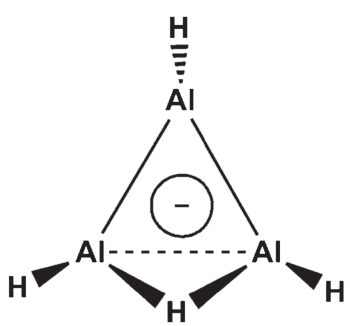

$\mathrm{Al}_{3} \mathrm{H}_{4}{ }^{-}$

42

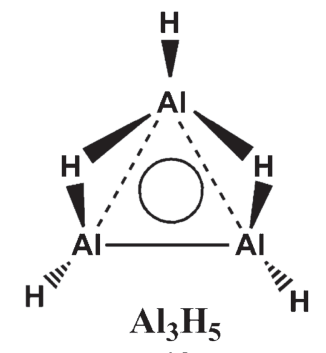

43

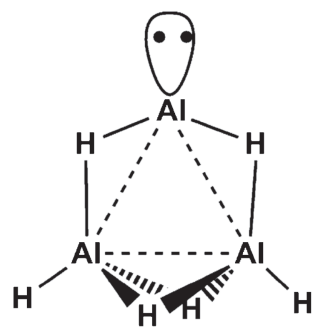

$\mathrm{Al}_{3} \mathrm{H}_{6}^{+}$

44

Figure 13. Most stable structures of $\mathrm{B}_{3} \mathrm{H}_{n}^{m}, \mathrm{~B}_{2} \mathrm{AlH}_{n}^{m}, \mathrm{BAl}_{2} \mathrm{H}_{n}^{m}$ and $\mathrm{Al}_{3} \mathrm{H}_{n}^{m}(n=3-6, m=-2$ to $+1)$ calculated at B3LYP/6-311++G** level of theory.

$6.8 \mathrm{kcal} / \mathrm{mol}$ more stable than the classical $D_{3 h}$ structures (32 and 33, figure 12) for $\mathrm{Al}$ and $\mathrm{Ga}$, respectively. Although the structure similar to the global minima of $\mathrm{Al}_{3} \mathrm{H}_{3}^{2-}$ and $\mathrm{Ga}_{3} \mathrm{H}_{3}^{2-}$ for $\mathrm{B}_{3} \mathrm{H}_{3}^{2-}$ is a minimum, it is $58 \mathrm{kcal} / \mathrm{mol}$ higher in energy than the most stable one at B3LYP/6-311+G* level of theory, which highlights the dramatic difference between $\mathrm{B}$ and its heavier analogues. It is interesting to note that an isomer similar to $\mathbf{3 0}$ and $\mathbf{3 1}$ is the global minimum for the isoelectronic $\mathrm{Si}_{2} \mathrm{BH}_{3}(29) .{ }^{24}$ Though the classical $D_{3 h}$ structure 32 for $\mathrm{Al}$ is also minimum, a similar structure $\mathbf{3 3}$ for $\mathrm{Ga}$ is a transition structure for the interconversion of $C_{3 h}$ structures (6); the energy difference between $\mathbf{3 3}$ and $\mathbf{6}$ is negligible. A similar distortion from $D_{3 h}$ to $C_{3 h}$ is also seen in $\mathrm{Pb}_{3} \mathrm{H}_{6}{ }^{26}$ The experimentally determined X-ray structures $\left(\mathrm{Na}_{2}\left[\mathrm{Ga}_{3} \mathrm{R}_{3}\right]\right.$ and $\mathrm{K}_{2}\left[\mathrm{Ga}_{3} \mathrm{R}_{3}\right]$, where $\mathrm{R}=2,6-\mathrm{Mes}_{2} \mathrm{C}_{6} \mathrm{H}_{3}$ ) have $C_{3 h}$ symmetry. ${ }^{6}$ The bonding picture of $\mathbf{6}$ can be constructed from $\mathrm{Ga}-\mathrm{H}$ fragments in their singlet ground states with a $\sigma$ lone pair and two p orbitals in orthogonal planes. The $\sigma$ lone pair in Ga has high percentage of $s$ character and does not prefer to 

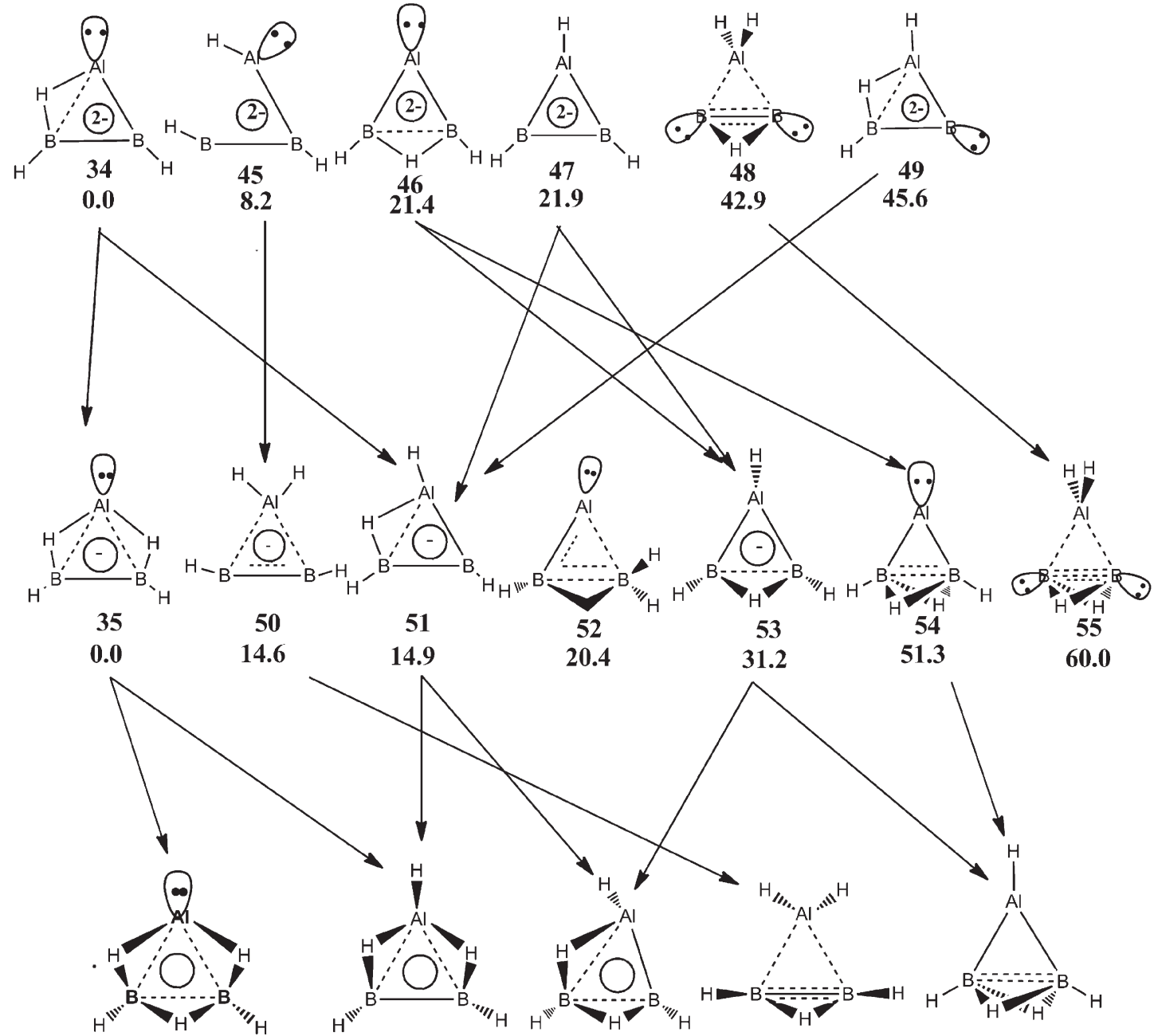

14.9

20.4

31.2

51.3

60.0

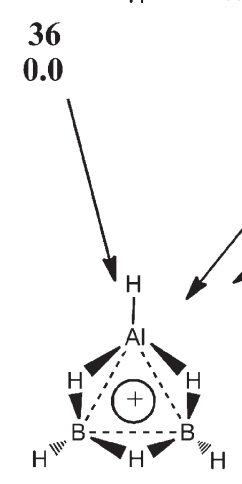

37
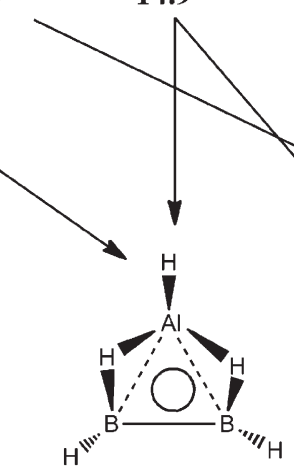

56

4.9

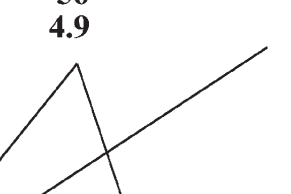

16.0

57

58

16.1

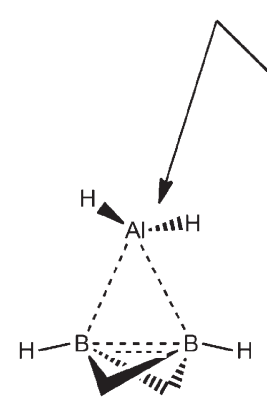

61

10.0
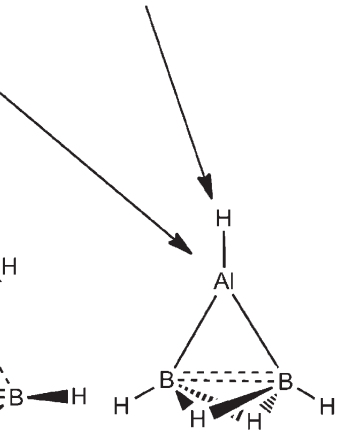

41.7

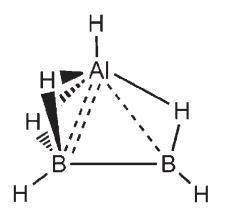

60

Figure 14. Protonation route of $\mathrm{B}_{2} \mathrm{AlH}_{n}^{m}(n=3-6, m=-2$ to +1$)$ isomers. Relative energies are calculated at B3LYP/6-311++G** level of theory.

form the traditional $\mathrm{sp}^{2}$ hybrid orbitals which are commonly observed in carbon and boron. Thus, the bonding of this structure (6) can be explained as a donor-acceptor complex of three singlet $\mathrm{Ga}-\mathrm{H}$ units as shown in scheme 4 , in which the lone pair of one $\mathrm{Ga}-\mathrm{H}$ unit is donated to the vacant $p$ orbital of the adjacent $\mathrm{Ga}-\mathrm{H}$ unit. The $\mathrm{Ga}-\mathrm{Ga}$ distance in $\mathbf{6}$ is about $0.07 \AA$ longer than those in the experimental structures, $\mathrm{Na}_{2}\left[\mathrm{Ga}_{3} \mathrm{R}_{3}\right]$ and $\mathrm{K}_{2}\left[\mathrm{Ga}_{3} \mathrm{R}_{3}\right]$.

Greater structural diversity has been observed when we go from the homocyclic three-membered ring systems to heterocyclic systems containing B and Al. The 
most stable structures of $\mathrm{B}_{3} \mathrm{H}_{n}^{m}, \mathrm{~B}_{2} \mathrm{AlH}_{n}^{m}, \mathrm{BAl}_{2} \mathrm{H}_{n}^{m}$ and $\mathrm{Al}_{3} \mathrm{H}_{n}^{m}(n=3-6, m=-2$ to +1$)$ are shown in figure 13. A dramatic structural alteration is observed as boron atoms in $\mathrm{B}_{3} \mathrm{H}_{n}^{m}$ are systematically substituted by aluminum atoms. ${ }^{27}$ The most stable structure of $\mathrm{B}_{3} \mathrm{H}_{3}^{2-}$ has a classical $D_{3 h}$ geometry. Similar structures for $\mathrm{B}_{2} \mathrm{AlH}_{3}^{2-}, \mathrm{BAl}_{2} \mathrm{H}_{3}^{2-}$ and $\mathrm{Al}_{3} \mathrm{H}_{3}^{2-}$ are higher energy minima on the PES of the respective species. A significant alteration in the most stable structure (34) occurs upon substitution of one of the boron atoms of $\mathrm{B}_{3} \mathrm{H}_{3}^{2-}$ by an aluminum atom. The most stable structure of $\mathrm{B}_{2} \mathrm{AlH}_{3}^{2-}$ has a bridging hydrogen atom at the $\mathrm{Al}-\mathrm{B}$ bond and a lone pair on the aluminum atom. Such structural alteration has emerged to accommodate the lone pair on the aluminum atom which results in planar tetracoordinated boron. Further substitution of the second boron atom by an aluminum atom results in $\mathrm{BAl}_{2} \mathrm{H}_{3}^{2-}(\mathbf{3 8})$. The most stable structure rearranges itself to attain a lone pair on both the aluminum atoms by efficiently keeping the bridging hydrogen at the weaker $\mathrm{Al}-\mathrm{Al}$ bond. A similar structure is most stable for $\mathrm{Al}_{3} \mathrm{H}_{3}^{2-}(\mathbf{3 0})$, but it is a first-order saddle point for $\mathrm{B}_{2} \mathrm{AlH}_{3}^{2-}$.

Unlike $\mathrm{B}_{3} \mathrm{H}_{3}^{2-}$ which has only one site $(\mathrm{B}-\mathrm{B}$ bond) available for protonation, the most stable structure of $\mathrm{B}_{2} \mathrm{AlH}_{3}^{2-}$ (34) has three different protonation sites (figure 14). These are the lone pairs on aluminum atom, the $\mathrm{Al}-\mathrm{B}$ bond and the $\mathrm{B}-\mathrm{B}$ bond. The protonation at the $\mathrm{Al}-\mathrm{B}$ bond leads to the most stable structure of $\mathrm{B}_{2} \mathrm{AlH}_{4}^{-}$(35), which has two bridging hydrogens at the $\mathrm{Al}-\mathrm{B}$ bonds and a lone pair on aluminum atom. Similar structure has been observed as first-order and second-order saddle points for the homocyclic boron and aluminum analogs, respectively. Protonation on the aluminum lone pair leads to the structure 51, which is $14.9 \mathrm{kcal}$ higher in energy than the global minimum structure; whereas protonation at the $\mathrm{B}-\mathrm{B}$ bond converges to the global minimum structure (35).

Structure 35 can undergo protonation either at the $\mathrm{B}-\mathrm{B}$ bond or at the lone pair on aluminum.

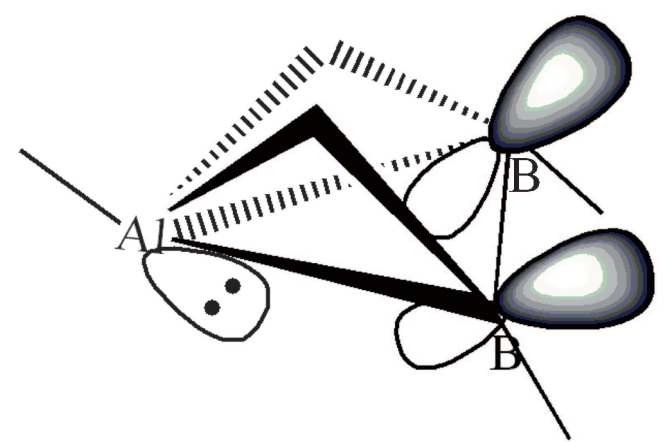

Scheme 5. Interaction of $\mathrm{Al}$ lone pair with the vacant $\pi$ $\mathrm{MO}$ of $\mathrm{B}_{2} \mathrm{H}_{4}$ fragment in $\mathbf{4 6}$.

Protonation at the $\mathrm{B}-\mathrm{B}$ bond gives rise to the most stable structure of $\mathrm{B}_{2} \mathrm{AlH}_{5}$ (36). It has three out-of-plane bridging hydrogen atoms and a lone pair on aluminum. It should be noted that the first and the second protonations on the most stable structure of $\mathrm{B}_{2} \mathrm{AlH}_{3}^{2-}$ retain the lone pair on aluminum atom (figure 14). The di- and triprotonated structures, $\mathrm{B}_{2} \mathrm{AlH}_{5}(\mathbf{3 6})$ and $\mathrm{B}_{2} \mathrm{AlH}_{6}^{+}(37)$ are similar to the most stable structure of $\mathrm{B}_{3} \mathrm{H}_{6}^{+}(\mathbf{1 9})$. Planar alternatives of these structures are second-order saddle points on the PES. The explanation given for the higher stability of non-planar structures over the planar one for the tri-bridged structure of $\mathrm{B}_{3} \mathrm{H}_{6}^{+}$holds good for structures $\mathbf{3 6}$ and $\mathbf{3 7}$ also. Protonation at the aluminum lone pair of structure $\mathbf{3 5}$ generates an interesting di-bridged structure (56, figure 14), where the bridging and terminal hydrogen atoms are not in the plane of the three-membered ring. Similar structure does not exist for $\mathrm{B}_{3} \mathrm{H}_{5}$. Electronic structure of the di-bridged $\mathrm{B}_{2} \mathrm{AlH}_{5}$ (56) will be discussed in detail later.

The most stable mono-protonated structure of $\mathrm{BAl}_{2} \mathrm{H}_{3}^{2-}$ (39) is similar to the most stable structures of $\mathrm{B}_{2} \mathrm{AlH}_{5}(\mathbf{3 6}), \mathrm{B}_{2} \mathrm{AlH}_{6}^{+}(\mathbf{3 7})$ and $\mathrm{B}_{3} \mathrm{H}_{6}^{+}(\mathbf{1 9})$ as all of these structures have three out-of-plane bridging hydrogens. It has lone pairs on both $\mathrm{Al}$ atoms, similar to the most stable structure of $\mathrm{BAl}_{2} \mathrm{H}_{3}^{2-}(\mathbf{3 8})$. The di- and
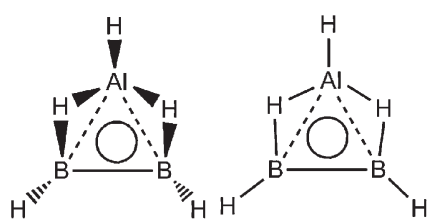

56

$0.0(0)$
63

$3.1(1)$

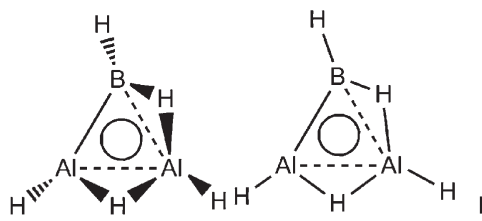

64

$0.0(0)$

7.7 (1)

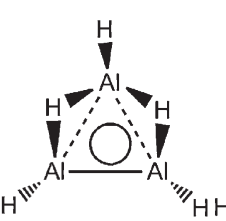

43

$0.0(0)$

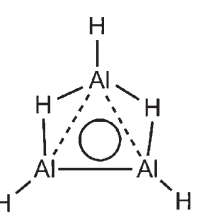

65

$18.0(2)$

Figure 15. Di-protonated structures of $\mathrm{B}_{2} \mathrm{AlH}_{5}$ (56 and 63), $\mathrm{BAl}_{2} \mathrm{H}_{5}$ (40 and 64) and $\mathrm{Al}_{3} \mathrm{H}_{5}(43$ and 65) showing the structures with non-planar hydrogen atoms are stabler than the planar structures. Relative energies $(\mathrm{kcal} / \mathrm{mol})$ at the B3LYP/6-311++ $\mathrm{G}^{* *}$ level of theory and the number of imaginary frequencies (in parenthesis) are given. 


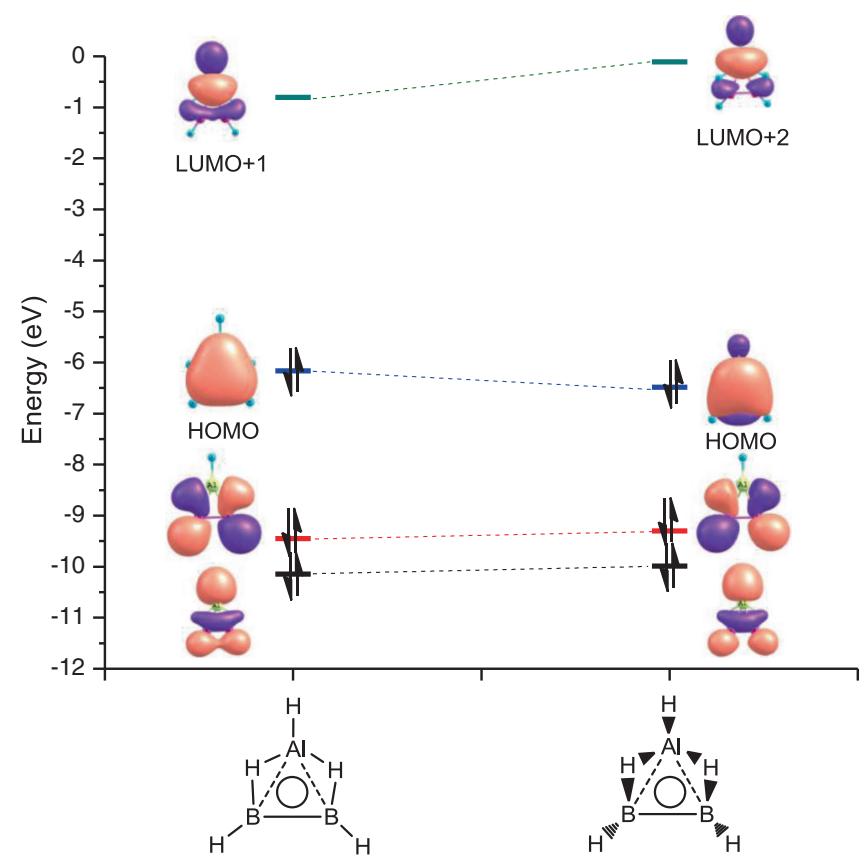

Figure 16. Correlation diagram showing stabilization of the $\pi$-MO in going from planar to non-planar structure.

triprotonated structures (40 and $\mathbf{4 1})$ of $\mathrm{BAl}_{2} \mathrm{H}_{3}^{2-}$ do not have lone pairs on aluminum atoms. The mono- and diprotonated structures of $\mathrm{Al}_{3} \mathrm{H}_{3}^{2-}(\mathbf{4 2}$ and $\mathbf{4 3})$ are similar to the most stable structures of $\mathrm{B}_{3} \mathrm{H}_{4}^{-}(\mathbf{1 7})$ and $\mathrm{B}_{3} \mathrm{H}_{5}$ (18), respectively, but the bridging and the terminal hydrogens are not in the plane of the three-membered ring. The most stable structure of $\mathrm{Al}_{3} \mathrm{H}_{6}^{+}$has a rather unusual structure (44). It has a planar tetracoordinated aluminum atom having a lone pair and two hexacoordinated aluminum atoms.

The protonation study reveals another interesting observation when we compare the di-protonated structure of $\mathrm{B}_{3} \mathrm{H}_{3}^{2-}$, i.e, $\mathrm{B}_{3} \mathrm{H}_{5}$ with those of mixed systems such as $\mathrm{B}_{2} \mathrm{AlH}_{5}$ and $\mathrm{BAl}_{2} \mathrm{H}_{5}$ as well as with
$\mathrm{Al}_{3} \mathrm{H}_{5} \cdot{ }^{27 \mathrm{~b}}$ As pointed out earlier, the most stable structure of $\mathrm{B}_{3} \mathrm{H}_{5}$ is a planar di-bridged structure (18). Similar structures for $\mathrm{B}_{2} \mathrm{AlH}_{5}, \mathrm{BAl}_{2} \mathrm{H}_{5}$ and $\mathrm{Al}_{3} \mathrm{H}_{5}$ are not minima (figure 15). The planar di-bridged structure for $\mathrm{B}_{2} \mathrm{AlH}_{5}(\mathbf{6 3})$ and $\mathrm{BAl}_{2} \mathrm{H}_{5}(\mathbf{6 4})$ are first-order saddle points whereas the same for $\mathrm{Al}_{3} \mathrm{H}_{5}$ (65) is a secondorder saddle point (figure 15). All these structures lead to non-planar structures $(\mathbf{5 6}, \mathbf{4 0}$ and $\mathbf{4 3}$ in figure 15) upon optimization along the direction of the imaginary frequency. It should be noted that similar non-planar structure does not exist for $\mathrm{B}_{3} \mathrm{H}_{5}$. The bonding description given earlier to explain the structure of planar $\mathrm{B}_{3} \mathrm{H}_{5}$ is not adequate to explain the non-planarity of the structures observed for $\mathrm{B}_{2} \mathrm{AlH}_{5}, \mathrm{BAl}_{2} \mathrm{H}_{5}$ and $\mathrm{Al}_{3} \mathrm{H}_{5}$. Higher stability of the non-planar structures over planar ones for $\mathrm{B}_{2} \mathrm{AlH}_{5}, \mathrm{BAl}_{2} \mathrm{H}_{5}$ and $\mathrm{Al}_{3} \mathrm{H}_{5}$ is due to the propensity of aluminum to retain the lone pair. Bonding in $\mathrm{B}_{2} \mathrm{AlH}_{5}$ can be described by the interaction between a planar $\mathrm{B}_{2} \mathrm{H}_{4}$ unit with a $\mathrm{Al}-\mathrm{H}$ unit. Here, a $\pi$-type $3 \mathrm{c}-$ $2 \mathrm{e}$ bond is formed by a donor-acceptor kind of interaction, where the lone pair of $\mathrm{Al}-\mathrm{H}$ fragment donates its lone pair to the vacant $\pi$-MO of the planar $\mathrm{B}_{2} \mathrm{H}_{4}$ unit as shown in scheme 5. Unlike non-planar $\mathrm{B}_{3} \mathrm{H}_{6}^{+}$, where the $\pi-\mathrm{MO}$ is stabilized through the interaction with the out-of-plane bridging hydrogens, ${ }^{15 a}$ for $\mathrm{B}_{2} \mathrm{AlH}_{5}$, stabilization of $\pi-\mathrm{MO}$ arises due to interaction with the lone pair of the $\mathrm{Al}-\mathrm{H}$ unit. A MO correlation diagram (figure 16) between the planar and nonplanar isomers showing the stabilization of the $\pi$-MO supports this bonding scheme. Similar bonding description applies to the non-planar structures of $\mathrm{BAl}_{2} \mathrm{H}_{5}$ and $\mathrm{Al}_{3} \mathrm{H}_{5}$.

A comparative study among the most stable structures of $\mathrm{B}_{3} \mathrm{H}_{6}^{+}, \mathrm{B}_{2} \mathrm{AlH}_{5}$ and $\mathrm{BAl}_{2} \mathrm{H}_{4}^{-}$and tri-hydrogen bridged structure of $\mathrm{Al}_{3} \mathrm{H}_{3}^{2-}$ brings out an interesting structural relationship (figure 17). Replacing one of

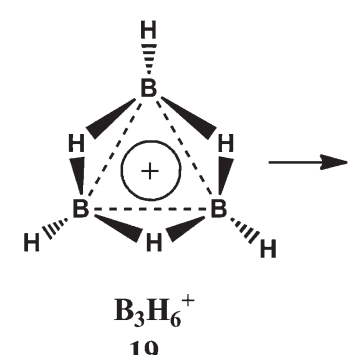

(a)

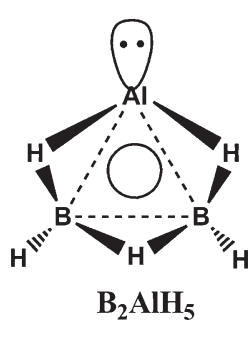

36

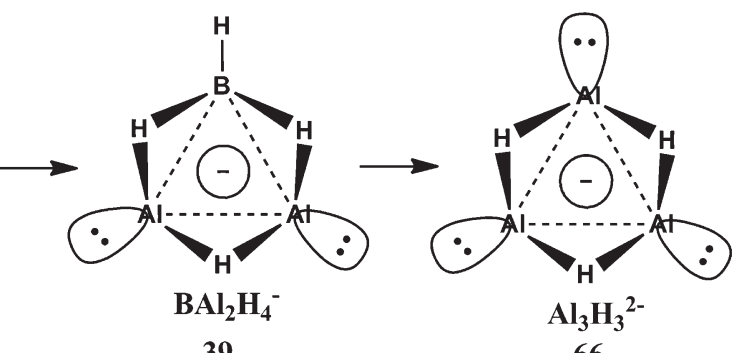

66

(b)

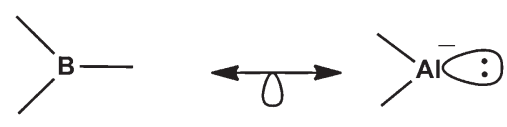

Figure 17. (a) Most stable structures of $\mathrm{B}_{3} \mathrm{H}_{6}^{+}, \mathrm{B}_{2} \mathrm{AlH}_{5}$ and $\mathrm{BAl}_{2} \mathrm{H}_{4}^{-}$and tri-hydrogen bridged structure of $\mathrm{Al}_{3} \mathrm{H}_{3}^{2-}$ showing (b) isolobal analogy between trivalent boron and divalent aluminum anion. 


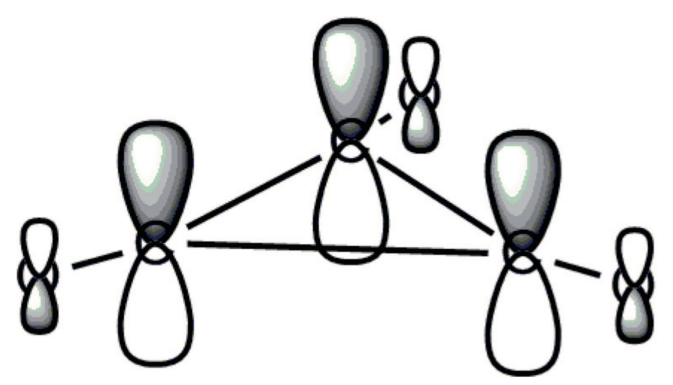

Figure 18. $\pi$-MO originates from $\pi^{*}$ MOs of each $\mathrm{CO}$ group in $\mathrm{C}_{3} \mathrm{O}_{3}^{2-}$ species.

the $\mathrm{BH}$ groups in $\mathrm{B}_{3} \mathrm{H}_{6}^{+}$(19) by $\mathrm{Al}^{-}$having lone pair results in the most stable structure of $\mathrm{BAl}_{2} \mathrm{H}_{5}(\mathbf{3 6})$. Similarly, systematic substitutions of the other two BH groups by $\mathrm{Al}^{-}$units lead to the most stable structure of $\mathrm{BAl}_{2} \mathrm{H}_{4}^{-}$(39) and a trihydrogen-bridged structure of $\mathrm{Al}_{3} \mathrm{H}_{3}^{2-}$ (66), respectively. The structure $\mathbf{6 6}$ is 7.9 $\mathrm{kcal} / \mathrm{mol}$ higher in energy than the most stable structure (30) at B3LYP/6-311+G* level of theory. ${ }^{25}$ This structural relationship indicates that there exists an isolobal analogy between trivalent boron and divalent aluminum anion (figure 17b).

\section{4. $2 \pi$-Aromaticity arising from $\pi *$ fragment molecular orbitals}

The traditional $2 \pi$-aromaticity of three-membered rings discussed so far originates from the overlap of pure $p$ orbitals perpendicular to the plane of the molecule. Aromaticity is also possible from the overlap of fragment molecular orbitals which are antibonding in the fragments. For example, $\mathrm{CO}$ has a pair of vacant $\pi^{*}$ orbitals. In the triangular $D_{3 h}$ arrangement of $(\mathrm{CO})_{3}$, bonding combination of the three $\pi^{*}$ MOs perpendicular to $\mathrm{C}_{3}$ plane is strongly $\mathrm{C}-\mathrm{C}$ bonding and very weakly $\mathrm{C}-\mathrm{O}$ antibonding. Occupancy of this MO (figure 18) gives $\mathrm{C}_{3} \mathrm{O}_{3}^{2-}$ which is a stable dianion and is synthesized. ${ }^{28} \mathrm{~A}$ similar delocalization involving pseudo $\pi *$ orbitals of $\mathrm{PF}_{3}$ is anticipated in the triangular $\left(\mathrm{PF}_{3}\right)_{3}$ so that its dianion is calculated to be aromatic (see figure 19). ${ }^{29}$

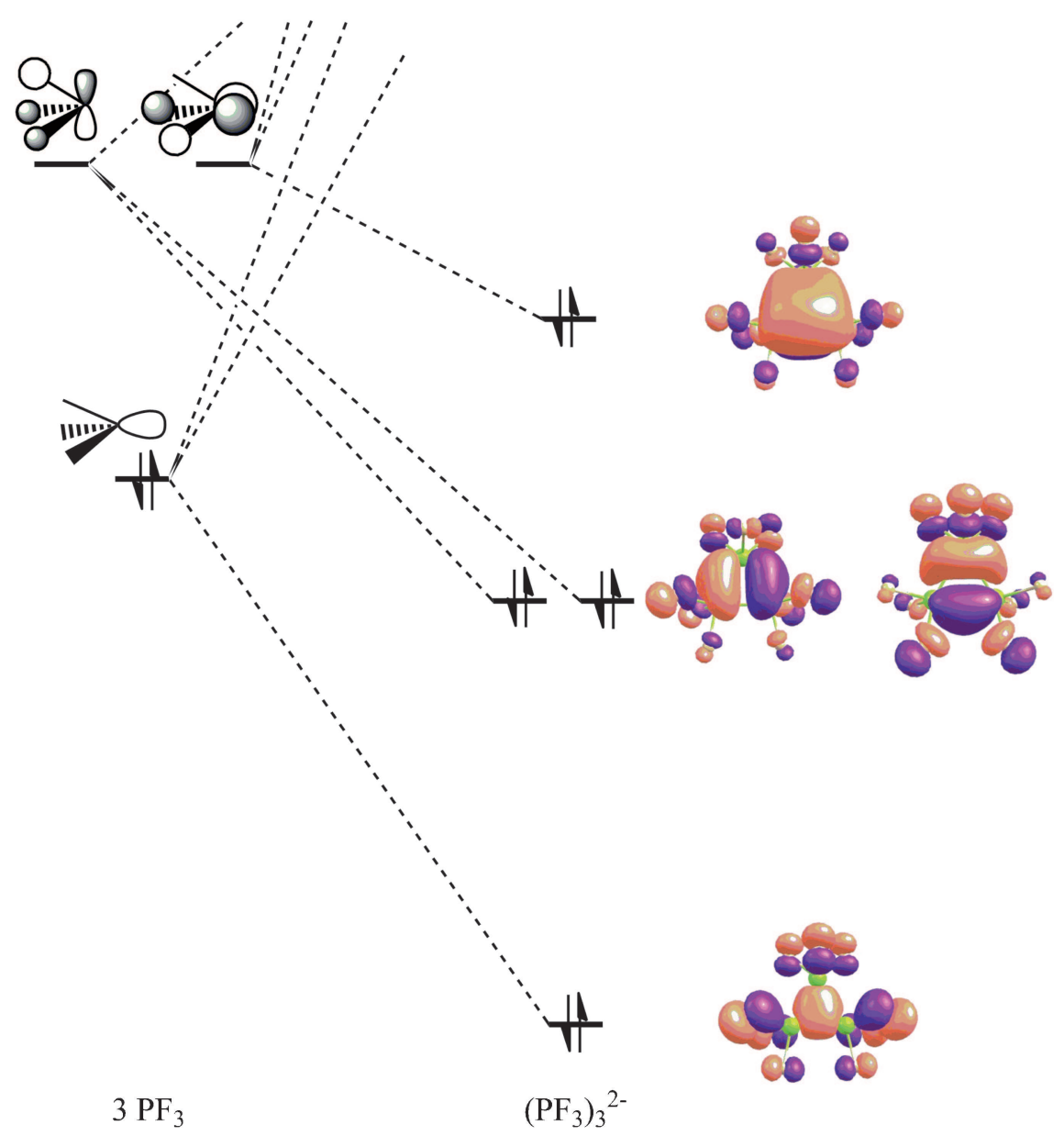

Figure 19. Qualitative fragment molecular orbital (FMO) diagram of $\left(\mathrm{PF}_{3}\right)_{3}^{2-}$ showing formation of $\pi$-MO from pseudo $\pi *-\mathrm{MO}$ of $\mathrm{PF}_{3}$ fragments. 


\section{Summary}

A comparative study between cyclopropenyl cation and its heavier analogues shows an emergence of fascinating structural diversity as we move down the group. It is observed that the structural pattern emerges for the heavier elements, especially beyond second group does not conform to the general norms of the carbon chemistry. For example, H-bridged structures are preferred over classical structure for heavier elements such as Ge, $\mathrm{Sn}$ and $\mathrm{Pb}$. Preference for $\mathrm{H}$-bridged structures is accounted by their tendency to retain a lone pair on them. The group 13 analogues of $\mathrm{C}_{3} \mathrm{H}_{3}^{+}$are also discussed. Non-planarity of the bridging and terminal hydrogens for the most stable structure of $\mathrm{B}_{3} \mathrm{H}_{6}^{+}$is due to the stabilization of the $\pi-\mathrm{MO}$ through interaction with the non-planar bridging hydrogens and minimization of steric repulsion between the terminal and the bridging hydrogen atoms. Isolobal replacement of one $\mathrm{B}-\mathrm{H}$ group in $\mathrm{B}_{3} \mathrm{H}_{5}$ with 14- electron metal fragment gives rise to a unique bonding pattern, showing reversal of the famous DCD model. Isolobal analogy between tricoordinated boron and divalent silicon is very useful in explaining the structures of $\mathrm{SiB}_{2} \mathrm{H}_{4}$. A dramatic structural diversity is observed in going from $\mathrm{B}_{3} \mathrm{H}_{3}^{2-}$ to $\mathrm{B}_{2} \mathrm{AlH}_{3}^{2-}, \mathrm{BAl}_{2} \mathrm{H}_{3}^{2-}$ and $\mathrm{Al}_{3} \mathrm{H}_{3}^{2-}$. This structural diversity is due to the preference of lower coordination on aluminum, higher coordination on boron and the higher multi-centre bonding capability of boron. A unique case of $\left(\mathrm{PF}_{3}\right)_{3}^{2-}$ is observed where $2 \pi$-aromaticity originates from the overlap of pseudo $\pi^{*}$ fragment molecular orbitals of three $\mathrm{PF}_{3}$ groups.

\section{Acknowledgements}

We thank the Supercomputer Education and Research Centre (SERC), Indian Institute of Science, Bangalore and the Centre for Modelling Simulation and Design (CMSD), University of Hyderabad for computational facilities. EDJ thanks the Department of Science and Technology (DST) for J C Bose Fellowship.

\section{References}

1. (a) Breslow R 1957 J. Am. Chem. Soc. 79 5318; (b) Breslow R and Groves J T 1970 J. Am. Chem. Soc. 92 (4) 984

2. (a) Walsh A D 1947 Nature 159 712; (b) Walsh A D 1949 Trans. Faraday Soc. 45179

3. (a) Hückel E 1931 Zeitschrift fur Physik 70 204; (b) Hückel E 1932 Zeitschrift fur Physik 76 628; (c) Hückel E 1937 Zeitschrift fur Elektrochemie und Angewandte Physikalische Chemie $\mathbf{4 2} 752$
4. Jemmis E D, Srinivas G N, Leszczynski J, Kapp J, Korkin A A and Schleyer P v R 1995 J. Am. Chem. Soc. 117(45) 11361

5. (a) Rubio J and Illas F 1984 J. Mol. Struct. 110 131; (b) Srinivas N G, Kiran B and Jemmis E D $1996 \mathrm{~J}$. Mol. Struct. 361205

6. (a) Li X W, Penninghton W T and Robinson G H 1995 J. Am. Chem. Soc. 117 7578; (b) Li X W, Xie Y, Schreiner P R, Gripper K D, Crittendon R C, Campana C F, Schaefer H F and Robinson G H 1996 Organometallics 15 3798; (c) Xie Y, Schreiner P R, Schaefer H F, Li X W and Robinson G H 1996 J. Am. Chem. Soc. 11810635

7. Srinivas G N, Jemmis E D, Korkin A A and Schleyer P V R 1999 J. Phys. Chem. A 10311034

8. Eisch J J, Shatii B and Rheingold A L 1987 J. Am. Chem. Soc. 1092526

9. Balucani N, Asvany O, Lee Y T and Kaiser R I 2000 J. Am. Chem. Soc. 12211234

10. Krogh-Jespersen K, Cremer D, Dill J D, Pople J A and Schleyer P V R 1981 J. Am. Chem. Soc. 1032589

11. Srinivas R, Sulzle D and Schwarz H 1990 J. Am. Chem. Soc. 1128334

12. Korkin A A, Schleyer P V R, Arx U V and Keese R 1995 Struc. chem. 6225

13. Wehrmann R, Meyer H and Bemdt A 1985 Angew. Chem. Int. Ed. Engl. 24788

14. (a) Korkin A A, Schleyer P v R and McKee M L 1995 Inorg. Chem. 34 961; (b) Schleyer P v R, Subramanian G and Dansfeld A 1996 J. Am. Chem. Soc. 118 9988; (c) McKee M L, Buhl M, Charkin O P and Schleyer P v R 1993 Inorg. Chem. 32 4549; (d) Krempp M, Damrauer R, DePuy C H and Keheyan Y 1994 J. Am. Chem. Soc. 116 3629; (e) Glukhovtsev M N, Schleyer P v R, Hommes N J R V E, Carn-Eiro J W D M and Koch W 1993 Comput. Chem 14285

15. (a) Jemmis E D, Subramanian G and Srinivas G N 1992 J. Am. Chem. Soc. 114 7939; (b) Skancke A and Liebman J F 1993 J. Mol. Struct.(THEOCHEM) 280 75; (c) McKee M L 1995 J. Am. Chem. Soc. 117 8001; (d) McKee M L 1999 Inorg. Chem. 38321

16. Schulenberg N, Wadepohl H and Himmel H-J 2011 Angew. Chem. Int. Ed. 5010444

17. Jemmis E D and Subramanian G 1995 Inorg. Chem. 346559

18. Arunan E and Mandal P K 2001 J. Chem. Phys. 1143880

19. Hari Krishna Reddy K and Jemmis E D 2013 Dalton Trans. 4210633

20. Braunschweig H, Dewhurst R D, Hammond K, Mies J, Radacki K and Vargas A 2012 Science 3361420

21. Braunschweig H, Damme A, Dewhurst R D and Vargas A 2013 Nat. Chem. 5115

22. (a) Jemmis E D, Prasad B V, Prasad P V A, Tsuzuki S and Tanabe K 1990 Proc. Ind. Acad. Sci. (Chem. Sci.) 102 107; (b) Jemmis E D, Prasad B V, Tsuzuki S and Tanabe K 1990 J. Phys. Chem. 945530

23. Subramanian G and Jemmis E D 1992 Chem. Phys. Lett. 200567

24. Subramanian G, Jemmis E D and Prasad B V 1994 Chem. Phys. Lett. 217296

25. Srinivas G N, Anoop A, Jemmis E D, Hamilton T P, Lammertsma K, Leszczynski J and Schaefer H F 2003 J. Am. Chem. Soc. 12516397

26. Srinivas G N, Kiran B and Jemmis E D $1996 \mathrm{~J}$. Mol. Stru. THEOCHEM 361205 
27. (a) Jemmis E D and Parameswaran P 2007 Chem. Eur. J. 13 2622; (b) Mallick D, Parameswaran P and Jemmis E D 2008 J. Phys. Chem. A 1123080

28. (a) Eggerding D and West R 1975 J. Am. Chem. Soc. 97 207; (b) Eggerding D and West R 1976 J. Am. Chem.
Soc. 98 3641; (c) Summerscales O T, Cloke F G N, Hitchcock P B, Green J C and Hazari N 2006 Science 311829

29. Priyakumari C P and Jemmis E D $2013 \mathrm{~J}$. Am. Chem. Soc. 13516026 